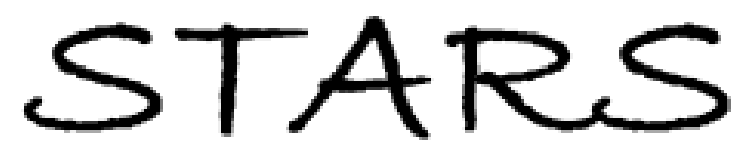

University of Central Florida

STARS

$1-1-2013$

\title{
Silicon-on-nitride waveguides for mid- and near-infrared integrated photonics
}

\author{
Saeed Khan \\ University of Central Florida \\ Jeff Chiles \\ University of Central Florida \\ Jichi Ma \\ University of Central Florida \\ Sasan Fathpour \\ University of Central Florida
}

Find similar works at: https://stars.library.ucf.edu/facultybib2010

University of Central Florida Libraries http://library.ucf.edu

This Article is brought to you for free and open access by the Faculty Bibliography at STARS. It has been accepted for inclusion in Faculty Bibliography 2010 s by an authorized administrator of STARS. For more information, please contact STARS@ucf.edu.

\section{Recommended Citation}

Khan, Saeed; Chiles, Jeff; Ma, Jichi; and Fathpour, Sasan, "Silicon-on-nitride waveguides for mid- and nearinfrared integrated photonics" (2013). Faculty Bibliography 2010s. 4200.

https://stars.library.ucf.edu/facultybib2010/4200

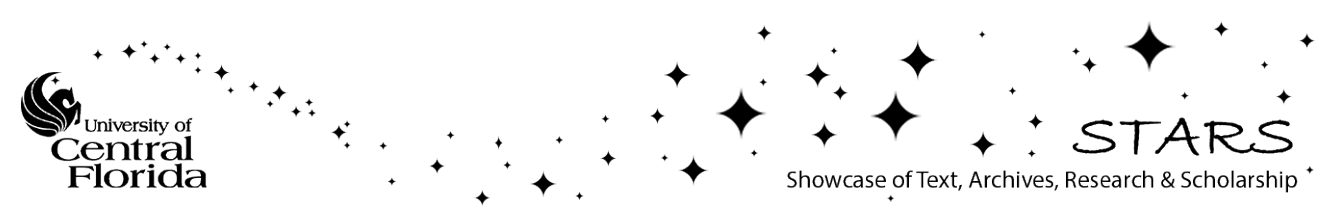




\section{Silicon-on-nitride waveguides for mid- and near-infrared integrated photonics}

Cite as: Appl. Phys. Lett. 102, 121104 (2013); https://doi.org/10.1063/1.4798557

Submitted: 21 December 2012. Accepted: 14 March 2013 . Published Online: 25 March 2013

Saeed Khan, Jeff Chiles, Jichi Ma, and Sasan Fathpour
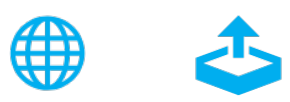

\section{ARTICLES YOU MAY BE INTERESTED IN}

Germanium-on-silicon nitride waveguides for mid-infrared integrated photonics

Applied Physics Letters 109, 241101 (2016); https://doi.org/10.1063/1.4972183

Planar silicon nitride mid-infrared devices

Applied Physics Letters 102, 251121 (2013); https://doi.org/10.1063/1.4812332

Silicon waveguides and devices for the mid-infrared

Applied Physics Letters 101, 121105 (2012); https://doi.org/10.1063/1.4753948

\section{Applied Physics Reviews} Now accepting original research 


\title{
Silicon-on-nitride waveguides for mid- and near-infrared integrated photonics
}

\author{
Saeed Khan, ${ }^{1,2}$ Jeff Chiles, ${ }^{1}$ Jichi Ma, ${ }^{1}$ and Sasan Fathpour ${ }^{1,2, a)}$ \\ ${ }^{1}$ CREOL, The College of Optics and Photonics, University of Central Florida, Orlando, Florida 32816, USA \\ ${ }^{2}$ Department of Electrical Engineering and Computer Science, University of Central Florida, Orlando, \\ Florida 32816, USA
}

(Received 21 December 2012; accepted 14 March 2013; published online 25 March 2013)

\begin{abstract}
Silicon-on-nitride ridge waveguides are demonstrated and characterized at mid- and near-infrared optical wavelengths. Silicon-on-nitride thin films were achieved by bonding a silicon handling die to a silicon-on-insulator die coated with a low-stress silicon nitride layer. Subsequent removal of the silicon-on-insulator substrate results in a thin film of silicon on a nitride bottom cladding, readily available for waveguide fabrication. At the mid-infrared wavelength of $3.39 \mu \mathrm{m}$, the fabricated waveguides have a propagation loss of $5.2 \pm 0.6 \mathrm{~dB} / \mathrm{cm}$ and $5.1 \pm 0.6 \mathrm{~dB} / \mathrm{cm}$ for the transverse-electric and transverse-magnetic modes, respectively. (C) 2013 American Institute of Physics. [http://dx.doi.org/10.1063/1.4798557]
\end{abstract}

Silicon photonics has become a mature integrated-optics technology for telecommunication or near-infrared (near-IR) wavelengths for some years. ${ }^{1}$ Extending the operating wavelength range of silicon photonics into the 3-5 $\mu \mathrm{m}$ or mid-wave infrared (MWIR or mid-IR) regime is a more recent field of research $^{2-15}$ with potential applications in chemical and biological sensing, tissue photoablation, environmental monitoring, and free-space communications. The initial mid-IR works were mostly on bulk silicon ingots. ${ }^{2-4}$ Mid-IR integrated silicon photonic devices have been emerging ${ }^{7-14}$ but more slowly due to the lack of high-beam-quality and high-power mid-IR laser sources and the associated problem of coupling light in and out waveguides efficiently. Another key challenge has been that the standard silicon-on-insulator (SOI) waveguides are not suitable for mid-IR, particularly in the 2.6-2.9 $\mu \mathrm{m}$ and $>3.7 \mu \mathrm{m}$ ranges, since the material loss of the buried oxide (BOX) layer becomes substantially high. ${ }^{5}$ Efforts have been made to eliminate overlapping of the optical mode with the lossy BOX cladding by demonstrating suspended silicon membrane waveguides on SOI. ${ }^{12}$ The silicon-on-sapphire (SOS) waveguide technology has also been pursued to extend the operating wavelength range up to $4.4 \mu \mathrm{m} .{ }^{7,11,13}$ Low-loss germanium strip waveguides on silicon have also demonstrated. ${ }^{14}$ Silicon-on-nitride (SON) waveguides, boasting a wide transparent range of $1.2-6.7 \mu \mathrm{m}$, have been proposed and theoretically analyzed. ${ }^{5,6,15}$ Here, SON waveguides are demonstrated and characterized at both mid-IR $(3.39 \mu \mathrm{m})$ and near-IR $(1.55 \mu \mathrm{m})$ wavelengths.

The bonding fabrication process is depicted in Fig. 1 and is described in the following. A SOI wafer and a silicon handling wafer were first diced into $2 \times 2 \mathrm{~cm}^{2}$ dies. The SOI die was then coated with a $1.3-\mu \mathrm{m}$ low-stress silicon nitride $\left(\mathrm{SiN}_{\mathrm{x}}\right)$ layer using the plasma-enhanced chemical vapor deposition (PECVD) process. Silicon nitride can be directbonded to the handling die after planarization by chemical mechanical polishing (CMP) ${ }^{16,17}$ or by using a spin-on-glass (SOG) layer. ${ }^{18,19}$ SOG was chosen in this work because of

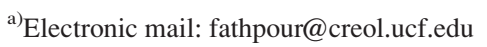

its low cost and ease of fabrication. Silicate-based SOG (20B) by Filmtronics was diluted with isopropyl alcohol (IPA) with a ratio of SOG:IPA $=1: 8$, resulting in a SOG layer of around $38 \mathrm{~nm}$ after $10 \mathrm{~min}$ of curing at $240{ }^{\circ} \mathrm{C}$. Thicker SOG layers (using higher SOG:IPA ratio) were avoided because they lead to striations that causes difficulties in the subsequent bonding step. Since SOG has low adhesion to silicon and silicon nitride surfaces, 50 -nm thick layers of PECVD silicon dioxide $\left(\mathrm{SiO}_{2}\right)$ were deposited on both the nitride layer (SOI die) and the silicon handling die before bonding. Thorough cleaning of the dies, by both the piranha solution and the RCA process, is essential for high-quality bonding. The cleaning steps also make the surfaces hydrophilic and strengthen the formed bonds. At initial roomtemperature, atmospheric-pressure bonding was performed by sandwiching the dies between two quartz slides and squeezing them with a steel clamp. A 60-min annealing at $450{ }^{\circ} \mathrm{C}$ in a nitrogen environment completes the bonding process. Then, about $400 \mu \mathrm{m}$ of the $500-\mu \mathrm{m}$ thick SOI substrate is removed by lapping, and the remaining $100 \mu \mathrm{m}$ is wetetched in tetramethylammonium hydroxide (TMAH) solution at $70^{\circ} \mathrm{C}$. Finally, the BOX layer is removed by diluted hydrofluoric (HF) acid solution exposing the SOI thin-film layer for waveguide processing. The SOG bonding is strong enough to survive the lapping and the following dicing and polishing processes for waveguide fabrication. It is noted that bonding at atmospheric pressure causes some undesired bubble formation in the achieved SON dies. This problem can be eliminated by bonding in vacuum, which is applicable for both direct and SOG-based bonding. ${ }^{18,19}$

Obviously, the buried $\mathrm{SiN}_{\mathrm{x}}$ layer should be thick enough to prevent leakage of the optical mode into the silicon substrate, the $\mathrm{SOG}$ layer, and the associated $\mathrm{SiO}_{2}$ adhesion layers. The required $\mathrm{SiN}_{\mathrm{x}}$ thickness and waveguide dimensions for single-mode condition at mid-IR wavelengths were designed by RSoft BeamProp simulations. Ridge waveguides with $2 \mu \mathrm{m}$ rib thickness, $0.8-\mu \mathrm{m}$ etch depth (1.2- $\mu \mathrm{m}$ slab thickness), and 2.0 to $2.5 \mu \mathrm{m}$ ridge widths were chosen for single-mode operation at the wavelength of $3.39 \mu \mathrm{m}$. The simulation results 


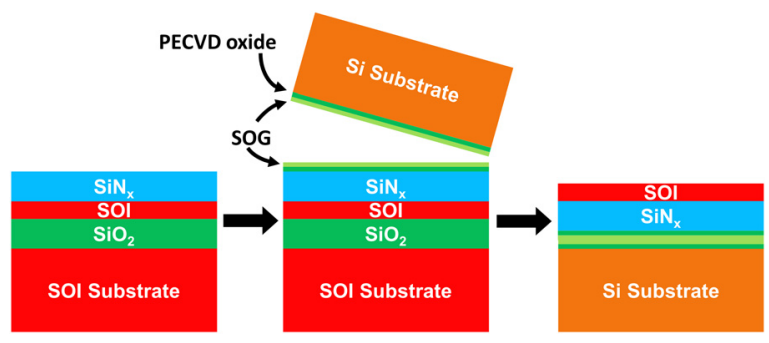

FIG. 1. Schematic of silicon-on-nitride die fabrication process.

(see the inset of Fig. 4(a)) show that for a $\mathrm{SiN}_{\mathrm{x}}$ thickness of $1.3 \mu \mathrm{m}$, there is negligible overlap of the optical mode with the SOG layer and the silicon substrate.

Based on the above design guidelines, ridge optical waveguides were fabricated on the SON dies using standard optical lithography and inductively coupled-plasma (ICP) dry etching of silicon using a 500-nm PECVD $\mathrm{SiO}_{2}$ hard mask. The employed SOI wafers had a $2-\mu$ m-thick top silicon layer on a $1-\mu \mathrm{m}$-thick BOX. The SOI substrate and the silicon handling wafers were both $500-\mu \mathrm{m}$ thick. The chips were diced into smaller dies that accommodate $<0.5$-cm-long L-shaped ridge waveguides. The waveguide facets were finally polished at highest attainable quality for optical transmission-loss measurements using end-butt coupling and the Fabry-Perot (FP) method. Figure 2 shows a scanning-electron-microscopic (SEM) image of the polished facet of a fabricated waveguide with air top cladding. The shiny layer observed in the middle of the $\sim 1.3-\mu$ m-thick silicon nitride layer is a measurement artifact due to the well-known charging effect of dielectric layers during SEM imaging.

The propagation loss, $\alpha$, of the achieved L-shaped SON waveguides was measured by the FP method, i.e., $\alpha$ was extracted from the modulation depth of the interference fringes $^{20}$

$$
\alpha L=\log \left(R \frac{1+\sqrt{P_{\min } / P_{\max }}}{1-\sqrt{P_{\min } / P_{\max }}}\right),
$$

where $P_{\min }$ is the minimum measured power, $P_{\max }$ is the maximum measured power in the FP fringes, $L$ is the waveguide length, and $R$ is the reflectivity of the waveguide facet. The radius of curvature of the L-shaped waveguides is $1 \mathrm{~mm}$, which is large enough to ignore any bending loss.

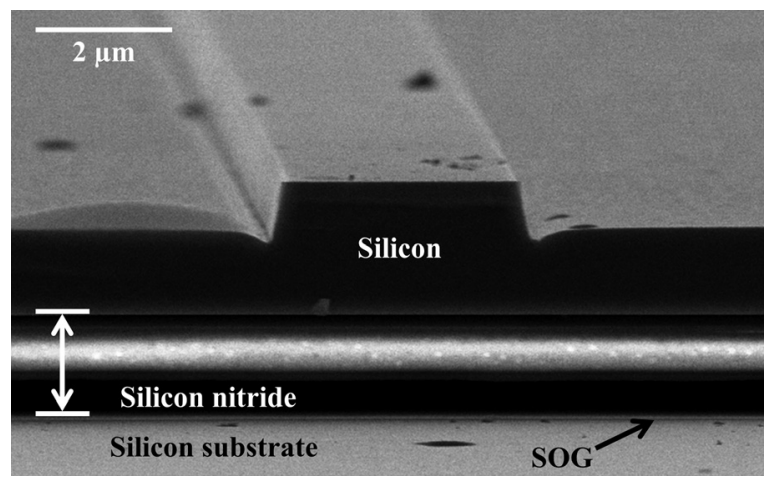

FIG. 2. SEM images of a fabricated silicon-on-nitride waveguide.
Figure 3 shows the schematic of our measurement setup at mid-IR wavelengths that includes the standard lock-in technique for signal amplification. A Newport 3.39- $\mu$ m HeNe laser with a maximum continuous-wave (CW) output power of $2 \mathrm{~mW}$ was employed. The FP fringes were obtained by sweeping the temperature of the chip using a thermoelectric cooler (TEC) controller. A mid-IR single-mode (SM) ZBLAN optical fiber from IRPhotonics was used to couple light into the waveguides, while a mid-IR multimode (MM) metal halide fiber was used for coupling the light out of the waveguides. Both the input and output fibers were non-tapered. ThorLabs' $\mathrm{PbSe}$ amplified detector (model\# PDA20H) was used for photodetection. Waveguides' temperature was scanned from $15^{\circ} \mathrm{C}$ to $58^{\circ} \mathrm{C}$ at a speed of $0.1{ }^{\circ} \mathrm{C} / \mathrm{s}$. Figure 4 (a) shows a measured transverse-electric (TE) mode transmission intensity modulation of a waveguide with $2.0-\mu \mathrm{m}$ ridge width and $3.65-\mathrm{mm}$ length. The inset shows the single-mode profile at $3.39 \mu \mathrm{m}$, obtained by RSoft BeamProp simulation. By conducting several similar measurements for $\mathrm{TE}$ and transverse-magnetic (TM) modes, propagation losses of $5.2 \pm 0.6 \mathrm{~dB} / \mathrm{cm}$ and $5.1 \pm 0.6 \mathrm{~dB} / \mathrm{cm}$ are, respectively, extracted from Eq. (1) at 3.39- $\mu \mathrm{m}$ wavelength. The TE and TM polarizations were achieved by simply rotating the polarized HeNe laser around its axis.

The waveguides were also characterized at near-IR wavelengths. A CW tunable laser at about $1.55 \mu \mathrm{m}$ was used to scan the wavelength and obtain FP fringes (see Fig. 4(b)). The extracted TE-mode propagation loss is $15.4 \mathrm{~dB} / \mathrm{cm}$ and the TM-mode loss is $15.6 \mathrm{~dB} / \mathrm{cm}$ at $1.55 \mu \mathrm{m}$. The near-IR TE-mode propagation loss was also measured by scanning the waveguide temperature using the TEC controller. The obtained value of $14.5 \mathrm{~dB} / \mathrm{cm}$ is fairly close to the above value obtained from wavelength scanning. To a certain extent, this consistency at the near-IR confirms the validity of the mid-IR measurements done merely by temperature scanning.

The right-hand inset of Fig. 4(b) shows the measured output mode profile of a SON waveguide at $1.55 \mu \mathrm{m}$, obtained by an infrared camera. Considering that the waveguides are L-shaped, the measured mode profile confirms that the optical energy is indeed guided in the core, since any significant coupling into the slab mode(s) would have been

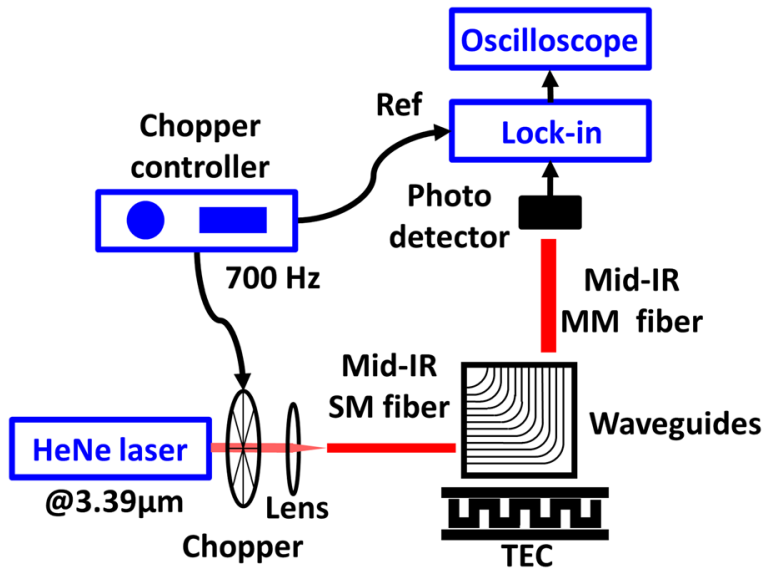

FIG. 3. Schematic of the experimental mid-IR setup used to characterize the silicon-on-nitride waveguides. 


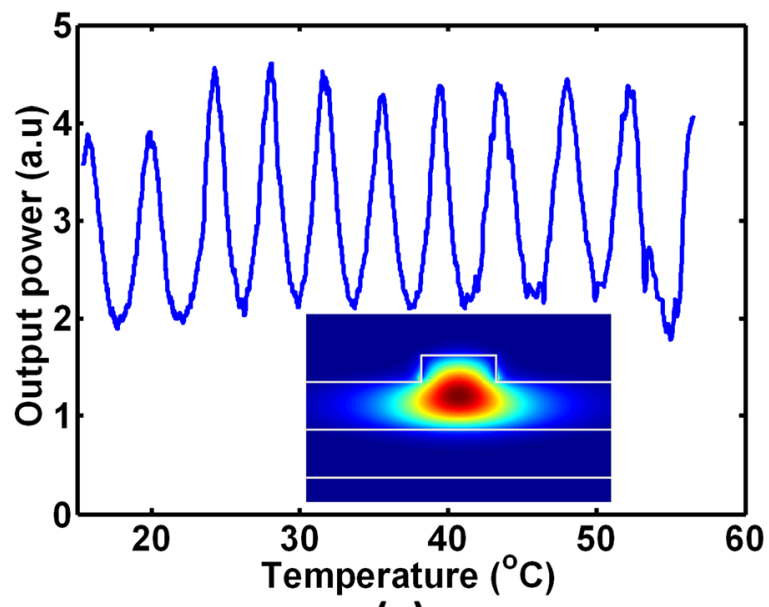

(a)

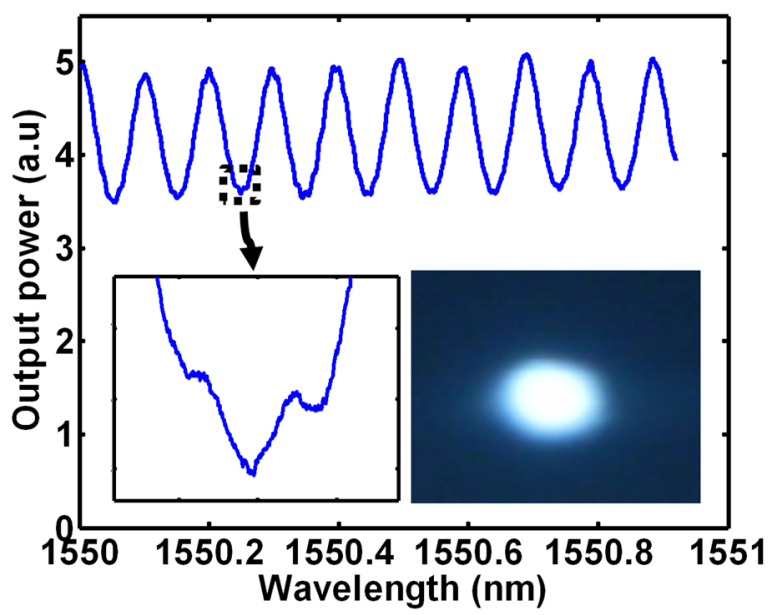

(b)

FIG. 4. (a) Measured TE-mode transmission intensity modulation obtained by scanning the temperature of a silicon-on-nitride waveguide at $3.39 \mu \mathrm{m}$ wavelength. The inset shows the mode profile of the single-mode SON waveguide at $3.39 \mu \mathrm{m}$, obtained from RSoft BeamProp simulation. (b) Measured TE mode transmission intensity modulation obtained by scanning the wavelength of a $1.55 \mu \mathrm{m}$ tunable laser. The right-hand inset shows the mode profile at $1.55 \mu \mathrm{m}$, obtained by an infrared camera. The left-hand zoomed region shows distortion in the scan caused by multimodeness.

lost in the bent regions. However, the measured single-lobe profile does not necessarily mean that the waveguides are single-mode at the near-IR. Actually, the reason for higher loss at near-IR compared to mid-IR is that the large crosssection waveguides $\left(\sim 2 \times \sim 2 \mu \mathrm{m}^{2}\right)$ are most likely multimode at $1.55 \mu \mathrm{m}$. Our BeamProp simulations confirm that by launching a $1.55 \mu \mathrm{m}$ TE input field into waveguides with widths of 2.1 to $2.5 \mu \mathrm{m}$, higher order modes exist in the structures. The TE-like components of these higher-order modes are symmetric and overlap the fundamental TE mode. A similar situation exists when a TM field is launched into the waveguides. As a result, the optical energy leaked from the fundamental mode into the higher-order modes can easily be lost to radiation modes in the bent regions of the L-shaped waveguides. The net effect is that the higher-order modes contribute to an extra loss term in the attained fundamental-mode FP fringes.

The near-IR multimodeness is also supported by our experimental results. It is known that multimodeness leads to distortion in the FP fringes. ${ }^{21}$ Slight distortion is evident in our scanned fringes as shown in the zoomed region of Fig. 4(b). Obviously, single-mode SON waveguides at near-IR can be achieved by fabricating smaller core crosssections, and then the real propagation loss at these wavelengths are expected to be comparable to the mid-IR values.

In summary, silicon-on-nitride waveguides are demonstrated and characterized at both mid- and near-IR wavelengths. At the mid-IR wavelength of $3.39 \mu \mathrm{m}$, the fabricated waveguides have a propagation loss of $5.2 \pm 0.6 \mathrm{~dB} / \mathrm{cm}$ and $5.1 \pm 0.6 \mathrm{~dB} / \mathrm{cm}$ for $\mathrm{TE}$ and $\mathrm{TM}$ modes, respectively. The demonstrated integrated photonic platform can extend the operating wavelength range of silicon photonics up to $6.7 \mu \mathrm{m}$ for a variety of biophotonic, sensing, and communication applications.

The work is being supported by the United States' National Science Foundation CAREER Program under Award Number ECCS-1150672.

${ }^{1}$ B. Jalali and S. Fathpour, J. Lightwave Technol. 24, 4600 (2006).

${ }^{2}$ B. Jalali, V. Raghunathan, R. Shori, S. Fathpour, D. Dimitropoulos, and O. Stafsudd, IEEE J. Sel. Top. Quantum Electron. 12, 1618 (2006).

${ }^{3}$ V. Raghunathan, D. Borlaug, R. R. Rice, and B. Jalali, Opt. Express 15, 14355 (2007).

${ }^{4}$ D. Borlaug, S. Fathpour, and B. Jalali, IEEE Photon. J. 1, 33 (2009).

${ }^{5}$ R. A. Soref, S. J. Emelett, and W. R. Buchwald, J. Opt. A, Pure Appl. Opt. 8, 840 (2006).

${ }^{6}$ R. Soref, Nature Photon. 4, 495 (2010).

${ }^{7}$ T. Baehr-Jones, A. Spott, R. Ilic, B. Penkov, W. Asher, and M. Hochberg, Opt. Express 18, 12127 (2010).

${ }^{8}$ X. Liu, R. M. Osgood, Y. A. Vlasov, and W. M. J. Green, Nature Photon. 4, 557 (2010).

${ }^{9}$ S. Zlatanovic, J. S. Park, S. Moro, J. M. C. Boggio, I. B. Divliansky, N. Alic, S. Mookherjea, and S. Radic, Nature Photon. 4, 561 (2010).

${ }^{10}$ G. Z. Mashanovich, M. M. Milošević, M. Nedeljkovic, N. Owens, B. Xiong, E. J. Teo, and Y. Hu, Opt. Express 19, 7112 (2011).

${ }^{11}$ Z. Cheng, X. Chen, C. Y. Wong, K. Xu, C. K. Y. Fung, Y. M. Chen, and H. K. Tsang, IEEE Photon. J. 4, 104 (2012).

${ }^{12}$ Z. Cheng, X. Chen, C. Y. Wong, K. Xu, and H. K. Tsang, IEEE Photon. J. 4, 1510 (2012).

${ }^{13}$ F. Li, S. D. Jackson, C. Grillet, E. Magi, D. Hudson, S. J. Madden, Y. Moghe, C. O'Brien, A. Read, S. G. Duvall, P. Atanackovic, B. J. Eggleton, and D. J. Moss, Opt. Express 19, 15212 (2011).

${ }^{14}$ Y. Chang, V. Paeder, L. Hvozdada, J. Hartmann, and H. P. Herzig, Opt. Lett. 37, 2883 (2012).

${ }^{15}$ Y. Yue, L. Zhang, H. Huang, R. G. Beausoleil, and A. E. Willner, IEEE Photon. J. 4, 126 (2012).

${ }^{16}$ S. Sánchez, C. Gui, and M. Elwenspoek, J. Micromech. Microeng. 7, 111 (1997).

${ }^{17}$ C. Gui, M. Elwenspoek, J. G. E. Gardeniers, and P. V. Lambeck, J. Electrochem. Soc. 145, 2198 (1998).

${ }^{18}$ A. Yamada, T. Kawasaki, and M. Kawashima, Electron. Lett. 23, 39 (1987).

${ }^{19}$ A. Yamada, T. Kawasaki, and M. Kawashima, Electron. Lett. 23, 314 (1987).

${ }^{20}$ G. Tittelbacht, B. Richter, and W. Karthet, Pure Appl. Opt. 2, 483 (1993).

${ }^{21}$ G. T. Reed and A. P. Knights, Silicon Photonics: An Introduction (John Wiley \& Sons, Ltd., West Sussex, England, 2004), p. 96. 